\author{
VITRUVIUS: THE WRITING OF AN OLD ARCHITECT - CENTURY I \\ B.C.
}

DOI: http//dx.doi.org/10.15448/21778-3748.2018.2.27055

\author{
Natália Munaro de Leão \\ Mestre em História - PUCRS \\ Especialista em egiptologia - IEPOA/Universidade Autônoma de Barcelona \\ nataliadeleao@gmail.com
}

\begin{abstract}
RESUMO: O Tratado de Arquitetura de Vitrúvio se apresenta como única obra teórica sobre a arquitetura grecoromana, legada pela Antiguidade. Portanto, ele se caracteriza, por si só, como uma fonte singular, que exerce grande influência em todos os profissionais e estudiosos. Entretanto, o tratado se destaca em importância por também possibilitar novas leituras históricas, uma vez que compreende conhecimentos que se manifestam além das técnicas e práticas arquitetônicas e construtivas, ao oferecer em seus prefácios/preâmbulos e capítulos uma escrita com caráter autobiográfico, detentora da escrita de si. Este estudo tem como objetivo, portanto, analisar a obra do arquiteto antigo Vitrúvio dentro do contexto de um registro da Escrita de $\mathrm{Si}$, como uma espécie de diário de um aluno/professor, o que pode contribuir para o conhecimento da história do período ao revelar, através dos seus escritos, o pensamento do autor, suas experiências, valores morais e culturais e a memória de sua profissão no contexto do século I a.C. - logo, do momento de transição da República para o Império Romano e, consequentemente, de alterações fundamentais na sociedade e na arquitetura romana.
\end{abstract}

PALAVRAS-CHAVE: Arquitetura Romana. Vitrúvio. Escrita de si.

ABSTRACT: Vitruvius's treatise On Architecture presents itself as the only theoretic work on Greco-Roman architecture bequeathed by Classical Antiquity. Thus, it is characterized, by itself, as a singular source, which exerts great influence on all professionals and scholars. However, the treatise stands out in importance for also allowing new historical readings, as it comprises knowledge that manifests itself beyond the architectonic and constructive techniques and practices, by offering in its prefaces/preambles and chapters a writing of autobiographical character, vessel of a Self Writing. This study has as an objective, therefore, to analyze the work of the ancient architect Vitruvius in the context of a register of Self Writing, as a kind of diary of a student/teacher, what may contribute to the knowledge of the period's history by revealing, through his writings, the author's thoughts, experiences, moral and cultural values and the memory of his profession in the first century b.C. context - hence, of the moment of transition from the Republic to the Roman Empire and, consequently, of fundamental alterations in roman society and architecture.

KEYWORDS: Architecture; Vitruvius; Self Writing.

\title{
ESCRITA DE SI
}

A obra de Vitrúvio, o Tratado de Arquitetura, será trabalhada neste estudo a partir da perspectiva de uma escrita de si. Utilizando-se do constante interesse por um gênero específico de escritos, a escrita de si - que envolve diários, cartas, biografias e autobiografias -, esta 
pesquisa pretende se aprofundar nesse viés para demonstrar como se pode verificar os meandros dos pensamentos do arquiteto antigo através desse tratado, fonte para a investigação histórica (GOMES, 2004). Para tanto, propomos analisar o Tratado de Arquitetura com o objetivo de compreendermos um pouco a profissão do arquiteto Vitrúvio através da apresentação de prefácios/preâmbulos que precedem cada um dos livros do autor, textos que conferem um caráter autobiográfico à obra (PELLATI, 1944).

Buscamos trabalhar com a fonte vitruviana como uma escrita de si, uma vez que se pode considerar o tratado como uma obra na qual seu autor, Vitrúvio, pretende abordar um determinado assunto de forma didática e extensa. Ao mesmo tempo, analisamos o tratado como uma espécie de diário de um aluno/professor, uma compilação da obra em que foram registradas as principais particularidades sucedidas durante o tempo em que autor pôde estudar e conhecer a profissão de arquiteto (ENCICLOPÉDIA, 1977).

Podemos observar que Vitrúvio escreve sua obra como se estivesse produzindo uma espécie de diário, em uma escrita de si, reunindo e registrando todo seu conhecimento sobre arquitetura, pesquisas, estudos e memória de profissão. Portanto, torna-se fundamental para esse estudo estabelecer relações entre uma história da subjetividade e da cultura de um indivíduo (no caso, Vitrúvio) que pode influenciar uma escrita sobre a história da História Antiga (GOMES, 2004) e sobre o conhecimento do profissional em contribuição à memória arquitetônica de seu tempo.

Para fazer uma análise crítica de tal fonte, faz-se necessário que seja observada a ótica assumida pelo registro e como seu autor a expressa, verificando o que o mesmo diz que viu, sentiu e experimentou em relação ao acontecimento - no caso deste estudo, a arquitetura antiga. De acordo com Gomes (2004), existem textos da escrita de si que se voltam para o registro de fases específicas de uma vida, como, por exemplo, experiências e estudos de trabalhos, os quais se constituem como um lugar da memória e traduzem um período excepcional, o que se verifica no objeto de pesquisa deste trabalho.

Pretendemos trabalhar o tratado de Vitrúvio como uma escrita de si que registra dados de seu conhecimento sobre sua profissão de arquiteto na Antiguidade; mesmo que sua obra se caracterize pelo distanciamento de uma escrita íntima, por ser produzida para a memória pública da arquitetura romana, seus textos, muitas vezes, introduzem sua opinião, além de apresentarem um caráter mais pessoal nos preâmbulos. Em cada preâmbulo da obra observamos certa literariedade, porém se sobressai a objetividade e o discurso denotativo sobre suas experiências. Para tanto, devemos tratar os registros de Vitrúvio como uma forma de compreender a 
experiência de vida de um arquiteto em seu tempo e lugar, juntamente à possibilidade de verificar os indícios da cultura arquitetônica de sua época. Assim, poderemos constatar a importância da sobrevivência de sua obra para a posteridade ao compreender o pensamento do profissional de arquitetura no século I a.C.

\section{VITRÚVIO E OBRA}

Marco Vitrúvio Pollio viveu no século I a.C. Ele foi arquiteto, engenheiro, agrimensor, pesquisador e teórico romano. Vitrúvio ficou conhecido pelo tratado Da Arquitetura, em dez volumes, única obra teórica de arquitetura que nos legou a Antiguidade (HINTZEN-BOHLEN; SORGES, 2006). Estudos apontam que o autor nasceu provavelmente em 88 a.C. e faleceu em 26 a.C., período marcado por alterações fundamentais na arquitetura romana (STIERLIN, 1997).

O Tratado de Arquitetura de Vitrúvio é composto por dez livros, com informações sobre arquitetura, planejamento urbano, ordens gregas, técnicas, edifícios públicos e privados, materiais de construção, descrição de mecanismos de aplicação civil e militar, relógios e máquinas hidráulicas. Existem registros de que desenhos acompanhavam a obra, porém todas as ilustrações do autor sobre as descrições foram perdidas. A obra se caracteriza por ser a primeira teorização desenvolvida sobre arquitetura, manual de urbanismo, construção, decoração e engenharia que se conhece (MACIEL, 2007).

A obra Da Arquitetura, escrita no século I a.C., configura-se como o mais antigo tratado sobre arquitetura que chegou até nós. Contudo, esse tratado acolhe uma série de escritos gregos sobre a arquitetura, esboçando a concepção e as intenções dos seus construtores (STIERLIN, 2009). O tratado de Vitrúvio se configura como um testemunho fundamental e significativo da regulamentação política e social romana no campo artístico e construtivo (PELLATI, 1944). Por essa importância, o texto se constitui como referência fundamental na ligação da história da arte com o patrimônio antigo, com a construção da tradição clássica greco-romana e com o pensamento do profissional da Antiguidade entre nós. Além disso, o texto de Vitrúvio aplicase a todas as artes, pois apresenta elementos definidores do Belo, e, portanto, da Verdade. A arquitetura, na concepção vitruviana, propõe-se a imitar a natureza, de forma que a construção deveria seguir as proporções do corpo humano e seguir uma definição de estrutura baseada na solidez, na utilidade e na beleza (BROLEZZI, 2007).

A obra de Vitrúvio fornece ao leitor uma compreensão mais aprofundada sobre as técnicas da arquitetura romana. Sua obra resistiu ao devir histórico e nos transmite o conceito de 
Antiguidade dos indivíduos em seu período, informando sobre as intenções dos novos comportamentos artísticos, arquitetônicos e ornamentais. Ela permite-nos uma reflexão teórica única sobre o urbanismo, a arquitetura e a decoração dos edifícios da época, apresentadas pelas propostas vitruvianas e vinculadas também ao pensamento construtor da civilização romana em um dos seus períodos áureos - contextualizadas no domínio da Pax Romana pelo mundo antigo junto à sociedade e às artes de culturas sob influência romana -, revelando sua importância contemporânea às realizações clássicas e às épocas que se sucederam (MACIEL, 2007).

O tratado vitruviano de arquitetura surge como o ponto de chegada da época helenística, coincidindo com o fim da República. Em sua obra, Vitrúvio resumia o conhecimento técnico grego mais avançado, como fora transmitido ao longo do tempo nos livros e na prática real (FINLEY, 1963). A técnica grega foi vista progressivamente pelos romanos como arte. Os antecedentes gregos se encontram sempre patentes em toda obra vitruviana, sua menção aos gregos antigos reside na constante preocupação em pensar em formas helênicas, na procura por novas soluções romanas. $\mathrm{O}$ autor utiliza edifícios públicos para explicar as características que são e que não são de tradição romana, demonstrando admiração pelas construções gregas (MACIEL, 2007).

As referências que Vitrúvio faz aos modelos gregos e helenísticos, ao longo do tratado de arquitetura - como, por exemplo, em relação ao teatro -, revelam que Roma assistia a algumas implementações e que, por isso, podemos pensar que, em alguns campos, o tratado vitruviano pode ter sido instaurador, além de ser uma obra de divulgação e reflexão arquitetônica e urbanística (Idem, 2007). Por constituir-se como única obra sobrevivente dos teóricos romanos da arquitetura, pesquisadores utilizam os dez volumes do tratado vitruviano, que versam sobre a arte da construção, para buscar compreender as leis da estética romana quanto a templos, teatros, basílicas e monumentos funerários (STIERLIN, 1997).

Vitrúvio ensina, em seus textos, as técnicas tradicionais dos romanos e, consequentemente, dos gregos (BROLEZZI, 2007). Sabemos que os arquitetos geralmente escreviam livros sobre suas obras. O autor em questão, porém, registrou um conjunto de regras muito elaboradas que se supõe ter sido influenciado por outros autores gregos, que provavelmente copilaram gradativamente outros estudos no decorrer dos séculos precedentes (LAWRENCE, 1998). A obra de Vitrúvio refletia, assim, os pensamentos de seus percursores, de tal maneira que não favoreceu, em seus escritos, informações importantes sobre as novidades da arquitetura romana. Ao publicar seu tratado, ele não reconheceu os empreendimentos grandiosos do fim da República, além de não mencionar criações fantásticas sobre os edifícios 
construídos em seu tempo (STIERLIN, 1997). Apesar disso, o tratado vitruviano de arquitetura não poderia ir além de seu conhecimento, pois, quando Vitrúvio publicou os dez volumes de sua obra, por volta de 31 a.C. a 25 a.C. - aproximado período que abrange a redação da obra, conforme as referências de monumentos contemporâneos a sua época (MACIEL, 2007; STIERLIN, 1997) -, ele não conhecia a maior parte das criações romanas no domínio arquitetônico, pois não foi contemporâneo ao apogeu dessa criatividade; portanto, seria impossível que sua obra refletisse o contributo essencial da arquitetura romana (Idem, 1997).

Segundo Stierlin (1997), Roma buscou inspiração na arte grega, contudo, as ordens arquitetônicas (dórica, jônica, coríntia e toscana) atribuíam uma função ornamental à arte romana; a essência do pensamento arquitetônico se encontrava na capacidade de criar e realizar obras que fossem originais em termos espaciais, através do arco, da abóbada e da cúpula. Vitrúvio não explorou este aspecto, mas defendeu um estilo tendencialmente clássico e tradicionalista que congelou a criatividade dinâmica dos construtores romanos do final da República. O autor optou por não explorar este aspecto talvez para mostrar certa contenção na arquitetura do início do Império, uma vez que esta seria uma manifestação de poder e poderia suscitar conflitos na política do período. Assim, as primeiras fases da arquitetura augustana não apresentam ostentações, entretanto, aos poucos, a partir da consolidação do poder imperial, a arquitetura grandiosa se desenvolveu até se difundir no reinado de Nero.

\section{DO ARQUITETO}

Analisaremos alguns trechos do texto vitruviano que não apenas remetem o leitor para suas pesquisas e trabalhos - resultantes do conhecimento adquirido por Vitrúvio ao longo de seu percurso como arquiteto -, mas que também podem indicar vestígios de uma escrita pessoal, quando aproximam à estrutura de diário. Deste modo, o tratado como fonte documental contribui para uma construção de uma história da escrita de si, uma vez que reúne informações sobre o autor, como suas opiniões, valores normativos, experiências e preocupações profissionais presentes em seu tempo. Isso possibilita compormos um estudo da memória do arquiteto no mundo antigo.

Em sua obra, Vitrúvio registrou toda sua contribuição para realizar a arte de edificar, mostrando a importância e a necessidade de se saber diversas disciplinas que contribuíssem para a formação do arquiteto: acústica hidráulica, geometria, ótica, astronomia, meteorologia, ciências naturais, medicina, pintura e escultura, história e filosofia (PELLATI, 1944). Neste trecho, por exemplo, são relacionados a ciência e o arquiteto: 
A ciência do arquiteto é ornada de muitas disciplinas e de vários saberes estando a sua dinâmica presente em todas as obras oriundas das restantes artes. Nasce da prática e da teoria [...] os [arquitetos] que se aplicaram numa e na outra coisa, como que protegidos por todas as armas, atingiram mais depressa, com prestígio, aquilo a que se propuseram (VITRÚVIO, Tratado de Arquitetura, I, 1, 1).

$\mathrm{Na}$ Antiguidade, Vitrúvio destaca, o arquiteto deveria conhecer literatura, desenho, geometria e aritmética:

Convém que o arquiteto conheça a arte literária, para que possa deixar uma marca mais forte através dos seus escritos. Também deverá ser instruído na ciência do desenho, a fim de que disponha da capacidade da mais facilmente representar a forma que deseja para as suas obras, através de modelos pintados.

A geometria, por sua vez proporciona à arquitetura muitos recursos [...] ensina o uso do compasso [...] através da óptica, se orientam corretamente os vãos de iluminação nas construções, a partir de determinadas zonas da abóbada celeste. [...] através da aritmética, se calculam as despesas dos edifícios se define a lógica das medidas e se encontram soluções para as difíceis questões das comensurabilidades através da lógica e de métodos geométricos (Idem, Tratado de Arquitetura, I, 1, 4).

Segundo Bovo (2007), na época de César e de Augusto, a profissão do arquiteto fora consolidada; este não era mais considerado um simples mestre-de-obras, mas um homem especialmente culto. A figura do arquiteto, além de dominar as disciplinas da profissão, como matemática, geometria e física, também deveria conhecer outras matérias para erguer construções. Tal conhecimento diversificado permitiu, segundo Hadas (1969), que os romanos abordassem de forma prática a arte da construção, fato que proporcionou que as formas arquitetônicas antigas não perdessem relevância nos tempos modernos. Diferentemente dos gregos, os romanos investiram em grandes construções de engenharia, como estradas, aquedutos e esgotos, que ajudavam na manutenção das cidades e na vida de seus habitantes.

Podemos observar, em Vitrúvio, esse conceito romano de arquiteto que refletia uma visão prática. A tal profissional não bastava saber só arquitetura, para realizar seu trabalho, seria necessário também ter conhecimento de medicina, para possibilitar a compreensão do clima, verificar os ares dos sítios, quais ambientes eram salubres ou pestilentos; deveria saber sobre a saúde do uso da água, para o abastecimento nas habitações construídas, e o posicionamento dos edifícios em lugares saudáveis. Para o profissional realizar seu trabalho era importante conhecer as regras do direito e suas leis, para se acostumar com o código das construções, também necessárias aos edifícios com paredes comuns, para evitar problemas com registros legais do 
edifício através de um contrato bem elaborado com o proprietário ou comprador. Além disso, o arquiteto antigo deveria ter um bom conhecimento de ótica, para estar apto para determinar a luminosidade no interior dos prédios; conhecer a astronomia para assim compreender o sistema dos relógios solares e orientar os monumentos; deveria possuir conhecimentos técnicos musicais para projetar um teatro, para resolver problemas relacionados à acústica, fazer órgãos hidráulicos e outras máquinas (HADAS, 1969; VITRÚVIO, Tratado de Arquitetura, I).

Segundo Martín (1992, p. 50), os romanos, por influência grega, deram o título de architectus para designar aqueles que

[...] monopolizaram o projeto e a construção de edifícios, a planificação de cidades, o cálculo e a construção de obras de abastecimento de água, de caminhos, de açudes, de muralhas, de portos e, curiosamente, o cálculo de relógios de sol e de tudo quanto se relacionasse com uma faceta importantíssima de mecânica antiga, como foram as máquinas de guerra.

Ao longo da história romana, algumas pessoas de cultura elevada, como o imperador Adriano, opinavam sobre questões estéticas e idealizavam edifícios e conjuntos arquitetônicos. A experiência arquitetônica de peritos militares era aplicada, quando necessário, na vida civil - como fez Vitrúvio, que, após sobreviver às guerras civis que geraram o Império Romano, na quais serviu como engenheiro militar, participando das campanhas de Júlio César, quando reformado, ofereceu ao imperador Augusto sua obra sobre arquitetura. Da mesma forma outros responsáveis administrativos legaram alguns documentos sobre suas funções e conhecimentos (Idem, 1992).

Dos dados conhecidos sobre os arquitetos profissionais, observamos que muitos de seus nomes eram gregos ou orientais - considerando a popularidade de nomes helênicos. Entre os arquitetos, existiam tanto os homens de origem livre, quanto os homens libertos - os quais eram, aliás, uma boa parte deles. Em sua maioria, eles provinham de camadas mais baixas ou intermediárias da sociedade romana. Em paralelo, gozavam de grande consideração profissional, mantinham laços de interesses com a família imperial ou a nobreza senatorial e provincial, destacando sua importância por assinarem as obras arquitetônicas por eles construídas. A profissão do arquiteto foi considerada a de mais elevada reputação e estima dentre as profissões de carácter artístico na Antiguidade (MARTÍN, 1992). No preâmbulo do primeiro livro, Vitrúvio indica sua ligação com a elite romana: "tendo-me tu [Augusto] inicialmente concedido o cargo, me mantivesse por recomendação de tua irmã" (VITRÚVIO, Tratado de Arquitetura, I, Pr. 3). 
$\mathrm{O}$ autor de que tratamos estava situado em uma categoria de funcionários subalternos ao poder romano, encarregados desde o exército até a justiça e o ensino. Os engenheiros e arquitetos eram muito influentes na ligação com o povo romano, principalmente com as elites, pois preparavam cultural e profissionalmente os indivíduos. Observa-se que suas preocupações com a história da arte, a filosofia e as teorias sobre as virtudes romanas são características presentes ao longo da obra Da Arquitetura (MACIEL, 2007).

Para Vitrúvio, o arquiteto deveria saber a importância do conhecimento histórico:

[...] convém que conheça muitas narrativas de fatos históricos, porque frequentemente os arquitetos desenham muitos ornamentos nas suas obras, de cuja razão de ser devem saber dar uma explicação, quando interrogados (VITRÚVIO, Tratado de Arquitetura, I, 1, 5).

Ele também precisaria mostrar interesse pela filosofia, pois ela "[...] torna o arquiteto magnânimo, para que não seja arrogante, mas sobretudo prestável, equitativo, digno de confiança e sem avareza, o que é fundamental" (Idem, Tratado de Arquitetura, I, 1, 7). Segundo Vitrúvio, a disciplina da arquitetura na Antiguidade exigia muita erudição e larga dedicação ao estudo, portanto, ele acreditava que essa profissão deveria ser instruída entre os meninos desde cedo, para que eles desenvolvessem o conhecimento da ciência, da maioria das letras e das artes, integrando disciplinas e acessando seus dados mais facilmente. Além disso, Vitrúvio afirmou que, mesmo imbuído de conhecimentos sobre os saberes disciplinares, sentia dificuldade em escrever sobre seu trabalho como arquiteto:

Como, por conseguinte, não é possível que, por inata inteligência, toda a gente, indistintamente, possa se beneficiar de tais conhecimentos, acessíveis apenas a alguns, e como o ofício de arquiteto deve ser exercido tendo em conta todos os saberes, pois a razão, devido à sua amplitude, não permita atingir a plenitude do conhecimento desejado, mas apenas um saber mediano das várias especialidades, peço, ó César, a tua compreensão e a daqueles que hão de ler estes livros [...] (Ibidem, Tratado de Arquitetura, I, 1, 18).

Através do texto de Vitrúvio, podemos verificar a preocupação do arquiteto com a dificuldade de conhecer profundamente todos os saberes, assim como também enfrentar os obstáculos e os problemas de registro do conhecimento. O profissional deveria prezar pelo cuidado ao escrever seus textos, de forma a mantê-los acessíveis à compreensão de todos e adequados para a divulgação de sua mensagem e perpetuação da memória da arquitetura:

Escrever sobre arquitetura não é o mesmo que escrever história ou poesia. As histórias, por si mesmas, entretêm os leitores. Com efeito, trazem várias expectativas de coisas novas. Por sua vez, a métrica e as sílabas dos cantos 
dos poemas, a disposição elegante das palavras e das frases entre personagens distintas e a recitação dos versos, atraindo os sentimentos dos leitores, transportam-nos sem dificuldades até a última página das obras.

Porém, isso não se verifica nos tratados de arquitetura, porque os vocábulos, concebidos pela própria especificidade da arte, trazem obscuridade à linguagem, por não serem de uso comum. Como eles, de per si, não são claro nem transparecem na língua corrente, se os escritos que longamente divagam sobre os preceitos não forem resumidos e explicados em pequenas e claras definições, tornam-se confusos para as mentes, devido à repetição e à prolixidade da terminologia. Nessas circunstancias, explorei brevemente os difíceis termos técnicos e as proporções das partes dos edifícios, para que sejam entregues à memória. $\mathrm{E}$, assim, as mentes poderão recebê-los de modo mais diligente (VITRÚVIO, Tratado de Arquitetura, V, Pr. 1-2).

Após apresentar tais dificuldades sobre a escrita da arquitetura, transformadas em constantes nos textos sobre o trabalho do arquiteto, Vitrúvio indica e opta por fazer abordagens mais objetivas e breves para melhor compreensão de todos:

[...] vendo que devo escrever sobre temas inusitados e difíceis para muitos a fim de que mais facilmente possam chegar ao entendimento dos leitores, resolvi produzir textos breves, porque assim serão de mais fácil percepção (Idem, Tratado de Arquitetura, V, Pr. 5).

Através da obra de Vitrúvio, podemos perceber que a formação, o conhecimento e a forma de trabalhar dos arquitetos romanos não eram adquiridas por formação acadêmicoteórica, mas que a profissão se consagrava após um longo aprendizado de caráter artesanal junto à experiência competente de algum profissional reconhecido. Dentre os conhecimentos do arquiteto, os de caráter perceptivo, ligados à realidade concreta, eram mais relevantes e trabalhados dos que os abstratos. Por meio do desenho das formas arquitetônicas se controlava, desde o projeto até sua execução, as formas da edificação (MARTÍN, 1992).

Em Vitrúvio, encontramos registrados o suporte e o papel da família e dos preceptores para a educação e a formação profissional do indivíduo na sociedade antiga. O autor manifesta sua gratidão aos pais e mestres, que proporcionaram a educação necessária para exercer sua profissão como arquiteto:

[...] a educação, conjugada com a força do ânimo, jamais se extingue, antes permanece estavelmente até o fim da vida.

Por isso, eu estou reconhecido e dou máximas e infinitas graças aos meus pais, porque, seguindo a lei ateniense, procuraram educar-me na arte, que não pode ser exercitada sem a aprendizagem da literatura e sem o conhecimento de todas as disciplinas. Como, pois, pelo cuidado dos meus progenitores e pelos sentimentos dos meus mestres eu obtivesse abundante cópia de conhecimentos deleitando-me nos temas literários e artísticos (VITRÚVIO, Tratado de Arquitetura, VI, Pr. 3-4). 
Vitrúvio ainda exaltaria o caráter do indivíduo no exercício da profissão, remetendo à importância da honestidade do arquiteto quando este desempenhasse suas atividades, não devendo então se dedicar ao estudo da arte para ganhar dinheiro ilicitamente: "descobri que mais vale a pobreza com boa fama do que a abundância com infâmia" (Idem, Tratado de Arquitetura, VI, Pr. 5). Vitrúvio sugere que, por seguir esse pensamento, talvez não tivesse conquistado celebridade em seu tempo, mas registrou que esperava que, com a publicação de sua obra, pudesse ser celebrado - devido a seu conhecimento - pela posteridade.

$\mathrm{O}$ antigo arquiteto relatou que a grande vontade de seus colegas de profissão residia no fato de seus projetos serem aceitos pela sociedade, contudo, ressaltou a importância de sempre atender e seguir os conselhos de seus preceptores:

[...] "Mais vale ser solicitado do que importunar, porque um semblante honesto cora de vergonha quando pede algo duvidoso. Com efeito, os que dão o benefício é que são solicitados, não os que recebem. Que diremos, pois, sobre o que pensará aquele a quem se roga para despender dinheiro em detrimento do próprio patrimônio, para proveito dos impetrantes, a não ser que isso redundará apenas em ganho e lucro destes últimos?" (Ibidem, Tratado de Arquitetura, VI, Pr. 5).

O autor do tratado também escreve sobre a existência de arquitetos considerados inexperientes no mundo antigo. Esses, segundo o autor, eram ignorantes e ineptos, não detendo qualquer conhecimento de arquitetura ou até de uma simples construção, colocando em causa, dessa forma, a grandiosa disciplina. Para tanto, Vitrúvio descreve a importância da procedência do arquiteto:

Por isso, os nossos maiores entregavam de preferência as suas obras a arquitetos recomendados pelo nascimento e depois procuravam saber se foram educados honestamente, julgando dever confiar na natural honradez e não na audácia aventureira. E como os próprios artistas apenas ensinavam os seus filhos ou parentes próximos, assim preparando aqueles homens bons a cuja integridade pudesse ser entregue sem hesitação os pagamentos de tantas coisas (VITRÚVIO, Tratado de Arquitetura, VI, Pr. 6).

Podemos perceber a preocupação de Vitrúvio com essa questão - ao mesmo tempo que promove sua integridade na profissão -, ao procurar enfatizar a diferença entre um leigo e um arquiteto:

Com efeito, todos os homens e não só os arquitetos, podem ajuizar acerca do que está bem, havendo a seguinte diferença entre os leigos e os outros: o leigo não pode saber o que vai ser realizado, a não ser quando o vir concluído, ao passo que o arquiteto já tem definido na sua mente, antes de iniciar a obra, 
como será construída esta em termos de beleza, funcionalidade e conveniência (Idem, Tratado de Arquitetura, VI, 8, 10).

Para vias de reconhecimento, Vitrúvio estabelece em sua obra uma relação proprietário-artista-arquiteto, para assim definir que todos os julgamentos dos edifícios obedeciam a uma tríplice consideração de sutileza construtiva, magnificência e disposição:

Quando se considera que a obra foi realizada com magnificência, serão louvadas as despesas feitas pela capacidade econômica do proprietário; quando se olha para a sutileza, a perfeição do artista será apreciada; mas, quando se apresentar esteticamente como modelo nas suas proporções e sistemas de medidas, então a glória será do arquiteto (Ibidem, Tratado de Arquitetura, VI, 8, 9).

São conhecidos vários nomes de arquitetos romanos que contribuíram para a arquitetura antiga com a construção de importantes obras de edifícios remanescentes por todo o Império, e ainda há comprovação da qualidade de muitos profissionais que permaneceram no anonimato. O mais conhecido de todos os arquitetos romanos foi Marco Vitrúvio Pollio, que dedicou a Augusto seu tratado de arquitetura, resumindo em sua obra seu conhecimento sobre teorias gregas e romanas. Provavelmente por sua experiência restrita - o único edifício sabidamente projetado por Vitrúvio foi um templo na cidade de Fano - e por concepções baseadas em leituras, não são relatadas grandes realizações técnicas e compositivas da arquitetura romana de seu tempo, remetendo-nos mais a informações que se aproximavam da arquitetura helenística (MARTÍN, 1992).

Segundo Martín (1992), Vitrúvio foi uma testemunha da transição da arquitetura helenística e romana. Sua erudição se conservou como o único texto antigo sobre essas temáticas, mesmo apresentando lacunas, e por se constituir como um texto obscuro - os desenhos da obra foram separados do texto e perdidos, deixando algumas explicações incompletas ou confusas. Não obstante, muito nos impressiona a quantidades de dados que a obra fornece e a extensão tamanha que possui. A qualidade de exemplar único e o grande uso que o Renascimento fez da obra transformou-a em bíblia dos arquitetos, chegando a ser tanto muito infamada quanto louvada.

\section{RENASCIMENTO}

A obra clássica de Vitrúvio, Da Arquitetura, tornou-se o manual mais famoso da Antiguidade dedicado à ciência da construção. Ela compunha-se de um exaustivo e minucioso 
tratado usado tanto como texto básico pelos arquitetos romanos como pelos da Renascença e exerceu grande influência nos mesmos profissionais (BOVO, 2007; HADAS, 1969).

O manuscrito mais antigo do texto vitruviano data do século IX e se encontra no Museu de Londres. As cópias mais antigas do tratado datam do período carolíngio. O manuscrito de sua obra foi descoberto em 1415, por Poggio Bracciolini, na biblioteca da abadia de St. Gall (STIERLIN, 1997). Até o século XV, conhecíamos cerca de 30 manuscritos da obra; a partir deste período, a quantia aumentou entre transcrições completas e extratos do tratado, chegando a, praticamente, uma centena. $O$ interesse renascentista pela Antiguidade contribuiu significativamente para tal expansão e divulgação da obra. Apenas o século XVI conta, entre edições e traduções, com duas centenas. A partir de então, surgiram outros estudos vitruvianos e edições que atingiram um alto grau de conhecimento crítico do Tratado de Arquitetura (MACIEL, 2007).

No Renascimento, a obra se tornou célebre por suas técnicas e formas de construções antigas, proporcionando aos arquitetos um material riquíssimo para pesquisa, como o foi para Leon Battista Alberti, que redigiu seu tratado de arquitetura (De Re Aedificatoria) baseado neste texto de Vitrúvio (HINTZEN-BOHLEN; SORGES, 2006). Nota-se que o conhecimento do arquiteto romano foi muito utilizado por seus colegas de profissão na época do Renascimento, na qual importantes profissionais produziram estudos fundamentados nos textos vitruvianos, sendo a antiga obra bastante comentada, citada e codificada. Em 1537, por exemplo, Sebastiano Serlio definiria os estilos clássicos da arquitetura através de Vitrúvio (STIERLIN, 1997). Em 1584, também se observaria o teatro Olímpico de Vicenza, que se tornaria modelo de muitos teatros construídos nesse período, ser construído segundo as orientações de Da Arquitetura (HADAS, 1969).

\section{CONCLUSÃO}

A obra de arquitetura de Vitrúvio se constitui como uma fonte primária singular para pesquisas ao se revelar como único tratado da Antiguidade que sobreviveu ao tempo. Ao analisarmos o tratado vitruviano pelo viés histórico dos escritos, percebemos um documento riquíssimo em informações ao conseguirmos extrair uma escrita de si do indivíduo-autor, uma testemunha de seu tempo, que registou os meandros do pensamento do arquiteto do passado. Em uma espécie de diário, o autor expressou as grandes preocupações de sua profissão no mundo antigo. 
Ao estabelecermos relações entre o tratado e a escrita se si, podemos realçar certos elementos na obra de Vitrúvio, principalmente por verificarmos, com a análise dos textos, a compreensão da importância da profissão de arquiteto no mundo romano, a qual deveria ser exercida por um indivíduo especialmente culto, que deveria possuir um conhecimento geral de diversas disciplinas, ou seja, a profissão exigia muita erudição e larga dedicação ao estudo interdisciplinar.

Por cumprirem tais requisitos, os arquitetos seriam muito influentes na sociedade antiga, uma vez que preparavam cultural e profissionalmente os indivíduos. Assim, os arquitetos também se encarregavam do ensino e das normas da justiça. Observamos, na escrita de Vitrúvio, a busca pelo acentuado conhecimento histórico e pela eloquência no discurso, o realce às virtudes romanas e a primazia do caráter do indivíduo no exercício de sua profissão. Os textos vitruvianos constituem-se como um bom exemplo de escrita que desempenharia um papel fundamental na educação dos indivíduos, além de fomentar o desenvolvimento de virtudes e características essenciais para formar, desde a juventude, bons profissionais

Em sua escrita, Vitrúvio registrou a importância do suporte e da contribuição da família e de preceptores para sua educação, além do valor de ser ensinado por um bom professor versado na arte da arquitetura. Para o arquiteto-autor, seus pares sempre deveriam manifestar admiração pelas normas e práticas estabelecidas pelos antigos, salientando, em sua obra, a valorização das tradições antigas greco-romanas. Ele também faz apologia à educação que recebeu e defende que, para um arquiteto, a educação, a sabedoria e a fama seriam conquistas muito mais importantes do que a busca pelo enriquecimento, visto que bens materiais podem ser extinguidos, enquanto as primeiras sempre se manteriam vigorosas ao longo da vida - ou até além - do indivíduo.

O autor também expressa, em seus escritos, suas preocupações e inquietudes com a profissão, como, por exemplo, a vontade de ter seu trabalho reconhecido e difundido perante a sociedade. Para tanto, ele toma nota de que o profissional deveria registrar seu conhecimento de forma adequada e acessível à compreensão de todos, uma vez que essa composição auxiliaria na ampla divulgação de sua mensagem e perpetuação do conhecimento da arquitetura. Para garantir prestígio e influência na sociedade romana, o autor mostrou a essencial integridade e distinção de seu parecer como arquiteto-profissional nas técnicas construtivas, que, uma vez registradas por meio de seu saber no tratado, permaneceriam inscritas na memória das futuras gerações. 
Vitrúvio soube traduzir na escrita de sua arte os anseios e expectativas do indivíduo romano como um profissional de seu tempo. Desta forma, a grande importância de sua obra para a escrita de si se revela ao realizar valiosos vínculos entre o fazer e seus sentidos morais, conforme a cultura predominante do período augustano. Portanto, em seus textos, revelou-se uma forma de escrita de si que produzia a memória do indivíduo arquiteto, com reflexos sociais de seu tempo, e que, portanto, deve ser guardada, lembrada e trabalhada. Ao analisarmos a fonte vitruviana sob a perspectiva de escrita de si, podemos compreender outra forma de estabelecer relações entre a história e a memória no século I a.C. através do pensamento de um indivíduo e de sua profíssão.

Notamos que Vitrúvio não registrou a arquitetura do período de Augusto. Contudo sua credibilidade procedeu do caráter de ser uma fonte escrita singular sobre a arquitetura grecoromana e, sobretudo, por ser a única conservada de um arquiteto antigo. Em seu tratado, percebemos a aspiração de converter essa profissão em uma arte liberal, visto que a arquitetura era e devia ser uma disciplina adornada de quase infinitas ciências ou porque o arquiteto deveria se adornar delas. Seu brilhantismo deve-se ao seu genial legado histórico, pois, além de registrar o que sabia, ele divulgou suas preocupações fundamentadas na excelência da arte de sua profissão. Devemos, assim, considerar seu conhecimento como pensamento de sua época.

A arquitetura romana continuou exercendo sua relevante influência nos tempos modernos pela sua praticidade e melhoria das cidades, com as construções de estradas, aquedutos e esgotos. O arquiteto Vitrúvio e sua obra Da Arquitetura permaneceram como referências básicas para assuntos relacionados à arquitetura até o período da Renascença. A cidade de Roma se consagrou, durante os séculos, como arquétipo das grandes metrópoles da Europa. Os métodos romanos de construção serviram para o desenvolvimento arquitetônico dos séculos seguintes e foram refletidos nos edifícios desses longos períodos. Roma transformou o mundo, seu legado alcançou diversas regiões e até continentes - inclusive os que os romanos jamais pensaram um dia existir e conquistar.

Constituído como obra de referência na Antiguidade, após redescoberto, séculos mais tarde, o tratado viria a influenciar as concepções estéticas renascentistas. Em relação à cultura romana, existem três períodos na história da arte europeia que marcaram um estilo - o românico, o Renascimento e o neoclassicismo - e que devem sua existência à Antiguidade romana e também à escrita do tratado vitruviano. Após tanto tempo, ainda hoje os arquitetos se referem às indicações que figuram na obra de Vitrúvio. 
O tratado, para sua época, constitui o legado do panorama do patrimônio cultural da antiguidade clássica - mesmo que não contemple o legado da fase áurea da arquitetura romana -, devido à abundância de conhecimento que transmite e pela ação exercida sobre a arte do Renascimento. Podemos, por isso, incluí-lo entre as obras fundamentais do pensamento humano. Vitrúvio conseguiu alcançar a glória que tanto almejava em sua obra. Depois de mais vinte séculos, ainda o veríamos ser favorecido e louvado, além de - como sempre acontece no fluxo da história - ser vítima de críticas.

Assim como Vitrúvio soube prestar agradecimentos à memória das gerações anteriores, sobre os méritos de muitos autores antigos, o autor romano também soube sabiamente transmitir por escrito - através de seu tratado - seu conhecimento às gerações vindouras, para que tal não se perdesse no decorrer dos tempos. Desta forma, ele proporcionou aos colegas sucessores da profissão que continuassem o desenvolvimento e o aperfeiçoamento das pesquisas sobre sua tão estimada arte, a arquitetura.

Os textos de Vitrúvio continuam a ser importantes tanto pelas suas ideias como pelo conhecimento que divulga. Isso se verifica, sobretudo, com os estudos que ainda lhe são dedicados. Além disso, sua obra conserva uma escrita reveladora de si, com informações sobre aspectos políticos e sociais vinculados aos arquitetos, sobre a formação profissional, as preocupações e os desejos dentro de seu contexto antigo. Contudo, com a análise da obra e seus reflexos posteriores ao Tratado de arquitetura, percebemos que, para estudar a arquitetura romana como um todo, verificar sua originalidade e seu caráter inovador, devemos ir além de Vitrúvio. Assim, é possível compreendermos o ideal dos construtores no mundo romano.

\section{DOCUMENTAÇÃO ESCRITA}

VITRÚVIO. Tratado de Arquitetura. Tradução de M. Justino Maciel. São Paulo: Martins Fontes, 2007.

\section{REFERÊNCIAS BIBLIOGRÁFICAS}

BOVO, Elisabetta (Coord.). Grande História Universal: a época do Império Romano. Barcelona: Folio, 2007. 5 v. 
BROLEZZI, R. Vitrúvio e sua herança moderna. In: VITRÚVIO. Tratado de Arquitetura. Tradução: M. Justino Maciel. São Paulo: Martins Fontes, 2007. p. 25-27.

ENCICLOPÉDIA Brasileira Globo. 15. ed. Porto Alegre: Editora Globo, 1977. 11 v.

FINLEY, M. I. Os Gregos Antigos. Lisboa: Edições 70, 1963.

GOMES, Ângela de Castro. Escrita de si, escrita da história. Rio de Janeiro: Editora FGV, 2004.

HADAS, Moses. Roma Imperial. Rio de Janeiro: José Olympio, 1969.

HINTZEN-BOHLEN, B.; SORGES, B. von J. Roma: arte e arquitetura. Königswinter:

Konemann, 2006.

LAWRENCE, A. W. Arquitetura Grega. São Paulo: Cosac \& Naify, 1998.

MACIEL, M. Justino. Introdução. In: VITRÚVIO. Tratado de Arquitetura. Tradução: M. Justino Maciel. São Paulo: Martins Fontes, 2007. p. 29-49.

MARTÍN, Alfonso J. Saber ver a arte etrusca e romana. São Paulo: Martins Fontes, 1992.

PELLATI, Francesco. Vitrubio: el gran arquitecto de la antiguedad greco-romana. Buenos Aires: Ediciones Clot, 1944.

STIERLIN, Henri. A Grécia: de Micenas ao Partenon. Lisboa: Taschen, 2009.

. O Império romano: dos etruscos ao declínio do Império romano. Colônia: Taschen, 1997. 
ARTIGO ACEITO PARA PUBLICAÇÃO EM: 03/11/2017

Oficina do Historiador, Porto Alegre, EDIPUCRS, v. 11, n. 2, jul./dez. 2018, 